\title{
Morte e finitude em nossa sociedade: implicações no ensino dos cuidados paliativos*
}

\author{
Death and finitude in our society: implications in palliative care education
}

Fermin Roland Schramm

*Apresentado na II Jornada de cuidados paliativos e dor: corpo mente e alma em foco. IN CA/H C1, Auditório M oacyr Santos Silva, 8ªndar, Praça Cruz Vermelha, 23, Centro - RJ, 25 a 27 de outubro de 2001. PhD, Pesquisador Associado da Escola N acional de Saúde Pública (EN SP-FIOCRUZ) e Consultor de Bioética do Instituto Nacional do Câncer (INCA). Recebido em janeiro de 2002.

\section{INTRODUÇÃO}

Para falar de como nossa sociedade considera a questão da morte e finitude humanas e quais implicações isso teria no ensino dos cuidados paliativos, uma das maneiras certamente mais legítimas e interessantes consiste em fazer uma pesquisa empírica sobre as percepções que as pessoas têm dos cuidados paliativos e compará-las com as práticas e o ensino dos cuidados paliativos.

No entanto, pode-se proceder também de outra maneira, começando pelo esclarecimento conceitual dos termos envolvidos no debate emergente sobre os cuidados paliativos, ver quais são os vínculos existentes entre os sentidos de cada termo e ver qual tipo de narrativa eles permitem ter.

Embora ambos os métodos sejam igualmente legítimos, considero a operação de esclarecimento dos termos condição necessária para um discurso correto sobre 0 ensino dos cuidados paliativos visto que permite em princípio evitar mal-entendidos sobre o que se está falando, sobre o que se pretende fazer e para quê.

Aqui adotarei o segundo caminho pois é com ele que lido melhor devido à minha formação de aprendiz de filósofo, o qual como ensinava Deleuze ${ }^{1}$ - deve tentar transformar as perguntas formuladas pelos outros em suas próprias perguntas, formuladas em sua linguagem própria, porque somente assim terá alguma chance de dizer algo de sensato e, eventualmente, de novo, ao invés de devolver ao interlocutor suas perguntas empobrecidas e distorcidas.

Para tanto iniciarei apresentando os conceitos de morte e finitude, articulados discursivamente com os outros dois conceitos - de vulnerabilidade e proteção - que considero necessários para dar o sentido pleno aos cuidados paliativos.

\section{MORTE, FINITUDE, VULNERABILIDADE E PROTEÇÃO}

Como ensinam as ciências da vida e da saúde e a reflexão filosófica e religiosa, mas também e sobretudo a própria experiência cotidiana: morte, finitude e - acrescentaria vulnerabilidade são características intrínsecas, ou ontológicas, dos sistemas vivos, os quais são sistemas jogados no M undo e situados no Tempo, submetidos portanto a um processo irreversível que inclui o nascer, o crescer, o decair e o morrer.

Trata-se de um fato irrefutável perante nossos sentidos imediatos: todos os seres vivos, inclusive os humanos, morrem. M orrem porque são vivos, porque como sistemas irreversíveis são "programados" biologicamente para morrer e, talvez, devam morrer para que outros seres da mesma espécie possam vir a 
ser. M as nossos sentidos podem nos trair: afinal continuamos a "perceber" o sol nascer embora saibamos pelo menos desde Copérnico que em realidade não é assim! Por isso, não podemos ter certezas acerca das crenças sobre nossa morte nem sobre uma eventual imortalidade de nosso eu que, evidentemente, não entrega os pontos tão facilmente. D e fato, a ciência teve poucas certezas ao longo de sua breve história, sendo que hoje ela não tem mais nenhuma e - como ensinou o pai da filosofia Sócrates - se a filosofia é uma sabedoria ela só permite ter uma única certeza, consistente em saber que de fato não sabemos nada.

Sendo assim, vida e morte devem ser consideradas como as duas faces inseparáveis (embora experiencialmente distinguíveis) da existência humana, durante a qual vida emorte são mediadas pelas situações de finitude chamadas vulnerabilidade. Por isso, para um dos homens mais poderosos de Roma, 0 estóico Sêneca (1 a.C. - 65 d.C.), viver é aprender a morrer; para o filósofo céptico francês M ichel de M ontaigne (1533 - 1592) filosofar é aprender a conhecer 0 aproximarse da morte [representado pela velhice] e para o filósofo existencialista alemão $M$ artin Heidegger, que foi um dos que mais meditaram sobre 0 assunto em nosso século, ${ }^{2}$ vivenciar o processo de viver e morrer, na condição de vulnerabilidade, faz parte da experiência humana enquanto ser-aí (D asein), isto é, de ser jogado no mundo e submetido aos efeitos devastadores do tempo, o que tornaria todo ser vivo humano de alguma forma consciente de ser um ser-para-a-morte.

$M$ as quando referimos esta situação da condição humana, definida pelos termos de vida, morte, tempo e vulnerabilidade aos pacientes ou usuários que são os sujeitos, objetos de nossa vocação e/ ou de nosso ofício enquanto profissionais da saúde, aparece inevitavelmente um outro termo: a proteção, a qual podedar sentido elegitimidade ao nosso agir profissional enquanto princípio ético de qualquer prática de cuidado.

Em outros termos, por ser lógica e discursivamente implicado pelo conceito de vulnerabilidade ou, melhor dito, de respeito da vulnerabilidade do outro, a proteção constitui em meu entender o primeiro princípio moral (no sentido do mais antigo, do mais importante e do mais geral) que orienta nosso agir com e sobre nossos semelhantes e todos os seres e entes que são objeto de nossa consideração, apreço e amor. D e fato, o sentido de "proteção" é o primeiro sentido da palavra grega ethos, encontrado pelos filólogos, da qual deriva nossa palavra ética que na origem (i.e. durante a época homérica no VIII S. a.C.) indicava a guarita para proteger os animais contra seus predadores, passando em seguida a significar o abrigo para os humanos se protegerem contra as ameaças externas. $M$ ais tarde $(\mathrm{V} s$. a. C.), com um sentido diretamente vinculado ao primeiro, ethos veio a indicar os costumes ou hábitos aceitos, aprendidos e incorporados pelas pessoas enquanto considerados necessários para o correto (= justo) exercício da cidadania e para garantir a convivência ordenada e pacífica entre cidadãos, tornandose portanto uma forma de proteção contra os maus costumes, considerados suscetíveis de criar a anomia social. Por fim, com Aristóteles (IV S. a.C.), ethos passou a indicar uma característica da personalidade, vindo mais tarde a significar, com o iluminista Kant (séc. XVIII), uma qualidade intrínseca do agente moral e abrindo 0 caminho para 0 exercício da autonomia pessoal, considerada evolutivamente 0 estágio da personalidade eticamente madura.

\section{COMO LIDA NOSSA SOCIEDADE COM TUDO ISSO?}

A pesar desses vínculos conceituais entre vida, morte, finitude, vulnerabilidade e proteção, existem dificuldades sérias em definir diretamente a morte visto que, em condições normais, não temos experiência direta dela. Com efeito, se é relativamente fácil ter uma experiência indireta da morte graças à morte dos outros, é quase impossível pensar na própria morte sem pensar também na própria vida e/ou em alguma vida após a morte. Em outros termos, a morte enquanto tal é praticamente impensável e quando, por alguma razão de força maior, ela se impõe à consciência e à elaboração, isso só se dá com muito sofrimento, em situações de vulnerabilidade e através as experiências 
sofridas do desamparo, que de fato são experiências dos seres humanos vivos que vivenciam a precariedade da condição humana mas não a morte.

Esta impossibilidade provavelmente explica 0 porquê as sociedades contemporâneas têm cada vez mais dificuldades em pensar a questão da morte e do morrer em seus aspectos de processo e em suas múltiplas significações, e isso apesar da sociedade contemporânea ter-se tornado uma sociedade do risco, na qual semultiplicam as ocasiões de experienciar a vulnerabilidade e enfrentar a morte em situações violentas de vários tipos. Este aparente paradoxo consistente no "recalque" do pensamento da morte, por um lado, e na persistência de ocasiões de experiência da morte e até na emergência de novas formas de violência e maneiras de experienciar a morte (a última das quais é agora o perigo o bioterrorismo), por outro - pode ser caracterizado, nos termos de $\mathrm{N}$ orbert Elias, como uma conseqüência do processo civilizador:

"Como outros aspectos animais, a morte, tanto como processo quanto como imagem mnemônica, é empurrada mais e mais para os bastidores da vida social durante 0 impulso civilizador. Para os próprios moribundos, isso significa que el es também são empurrados para os bastidores, são i solados". ${ }^{3}$

N esta mesma direção, o historiador francês Philippe Ariès, conhecido por seu célebre estudo sobre a morte no 0 cidente, $^{3}$ ao comparar a morte na Idade M édia e na Época Moderna, considera que na Idade $M$ édia a morte era menos ocultada devido ao fato do morrer ser considerado uma questão mais pública e menos privada. Para ele, na sociedade medieval as pessoas morreriam serenas e calmas, contrariamente à sociedade moderna, em que morrer ter-se-ia tornado ou um fato meramente privado ou totalmente recalcado. Agora - como faz notar Elias em suas críticas a Áries - se é tal vez correto dizer que a morte medieval era menos oculta que a atual (mas isso tampouco é seguro pois os efeitos da morte "estão aí" hoje também apesar de seu recalque!) e que se tratava de era um evento muito mais compartilhado pela comunidade, certamente é um exagero dizer que ela fosse mais tranqüila, visto que as pessoas tinham, por exemplo, menos meios para enfrentar as várias situações de vulnerabilidade. Como sintetiza Elias:

"A vida na sociedade medieval era mais curta; os perigos, menos controláveis; a morte, muitas vezes mais dolorosa; o sentido da culpa e o medo da punição depois da morte, a doutrina oficial. Porém, em todos os casos, a participação dos outros na morte de um indivíduo era muito mais comum. $\mathrm{H}$ oje sabemos como aliviar as dores da morte em alguns casos; angustias de culpa são mais plenamente recalcadas e talvez dominadas (...) $M$ as o envolvimento dos outros na morte de um indivíduo diminuiu." 4

U ma das razões deste afastamento dos moribundos "para os bastidores da vida social" (Elias, 0 p. Cit., p. 31) é certamente a assim chamada medicalização da vida, sobretudo graças à crescente incorporação tecnológica à medicina, fato, este, que permitiu praticamente estabilizar muitas doenças terminais, como no caso de doentes que podem ser mantidos artificialmente em vida durante longos períodos, senão indefinitivamente. $\mathrm{N} o$ entanto, nas mesmas sociedades tecnologicamente avançadas, cresce paralelamente a consciência da legitimidade moral da cultura do respeito da autonomia do paciente/usuário e, com isso, surge também uma nova atmosfera ao redor do morrer "na qual aparece questionada e relativizada a tarefa médica de fazer tudo 0 possível, mesmo contra os desejos do paciente, para impedir ou postergar a morte." ${ }^{5}$

Atualmente, os cuidados paliativos vêm justamente para preencher este espaço existente entre, por um lado, a competência técnica da medicina e da cura (que apesar dos incríveis avanços continua sendo limitada) e a cultura do respeito da autonomia do paciente no que se refere às suas decisões extremas, as quais implicam também em poder dizer quando não quer mais viver sofrendo.

$M$ as, para isso seja talvez necessário mudar a maneira de pensar a relação da vida 
e da morte, o que certamente é uma tarefa árdua, sobretudo se pensarmos que ela implica numa ferida narcísica profunda no desejo de onipotência de quem que seja.

\section{CONCLUSÃO}

0 que tem a ver tudo isso com o ensino em cuidados paliativos?

Em primeiro lugar, penso que a própria concepção de cuidados paliativos, por ser baseada (pouco importa se explicita ou implicitamente) no princípio da qualidade de vida para o paciente e seu entorno, muito mais do que naquele de sacralidade de vida, e por ter em conta a globalidade do paciente e de suas necessidades, constitui um complemento, senão uma alternativa, ao assim chamado positivismo médico graças a uma maior humanização das práticas de tratar e cuidar quem precisa.

Em segundo lugar, ao insistir sobre a integralidade da experiência do viver que implica o morrer, implica num novo enriquecimento metafísico para o jovem profissional, o qual poderá também se sentir mais confortado em suas inevitáveis frustrações profissionais.

Em terceiro lugar, os cuidados paliativostalvez delineiam uma espécie de justo meio constituído pela preocupação de responder ao chamamento do outro e ao mesmo tempo sem expropriálo da experiência fundamental de seu morrer.

\section{REFERÊNCIAS BIBLIOGRÁFICAS}

1. Deleuze G, Parnet C. D ialogues. Paris: Flammarion; 1977.

2. H eidegger $M$. Ser e tempo. Petrópolis: Vozes;1989. Tradução de: Sein und zeit.1927.

3. Elias N. A solidão dos moribundos. Rio de Janeiro: Jorge Zahar; 2001. p. 19.

4. Ariès P. 0 homem diante da morte. Rio de Janeiro: Francisco Alves; 1982.

5. Kottow M . Introducción ala bioética. Santiago: Ed. U niversitaria; 1995. p. 150. 